\title{
DECREASE IN PUPATION AND ADULT EMERGENCE OF Plutella xylostella (L.) TREATED WITH HEXAFLUMURON
}

\author{
Mohammad Mahmoudvand ${ }^{1,2 *}$, Habib Abbasipour ${ }^{1}$, Aziz Sheikhi Garjan³ ${ }^{\text {, and Ali Reza Bandani }}{ }^{4}$
}

The oligophagous pest Plutella xylostella (L.) is a major crucifer pest in Tehran Province, Iran. Hexaflumuron is an insect growth regulator insecticide with good effects on immature insect stages. The objective of this study was to investigate the effects of two sublethal concentrations $\left(\mathrm{LC}_{10}\right.$ and $\left.\mathrm{LC}_{25}\right)$ of hexaflumuron on some biological parameters of $P$. xylostella larvae, such as birth rate $(b)$, death rate $(d)$, finite rate of increase $(\lambda)$, generation time $(T)$, sex ratio, pupation rate, and adult emergence. Results showed that hexaflumuron decreased the total number of eggs and oviposition and post-oviposition periods, pupation, and adult emergence in the treated generation, $b$, and $\lambda$. Hexaflumuron also increased $T, d$, and the preoviposition period. However, sex ratio, percentage of pupation, and adult emergence in the offspring generation were not affected by hexaflumuron. Overall, these results indicated that sublethal concentrations of hexaflumuron can affect the biological parameters of P. xylostella.

Key words: Plutella xylostella, hexaflumuron, sublethal, birth rate, death rate, oviposition period.

$\mathrm{T}$ he diamondback moth Plutella xylostella (L.) (Lepidoptera: Yponomeutidae) is one of the most destructive pests of cruciferous crops in the world, including Iran. The pest is widely distributed all over the world and can attack a wide range of wild or cultivated Brassicaceae plants, including mustard (Sarfraz et al., 2006; Mahmoudvand et al., 2009). This insect is much feared because it easily develops insecticide resistance, although the selected pesticides used to control it belong to different chemical classes with unique modes of action; it has been ranked in the top 20 resistant insects worldwide. This pest is the first reported case of field resistance to Bacillus thuringiensis (Perez et al., 1995; Mota-Sanchez et al., 2002).

Sublethal concentrations of insecticides can influence the physiological and behavioral characteristics of insects (Haynes, 1988; Curkovic and Brunner, 2005; Curkovic et al., 2009), including larval and pupal weight (Jun et al., 1999), adult emergence (Yin et al., 2008), developmental time (Michaud and Grant, 2003; Golmohammadi et al., 2009), survival (Yin et al., 2008), and fecundity (Galvan

${ }^{1}$ Shahed University, Faculty of Agricultural Sciences, Department of Plant Protection, P.O. Box 18151/159, Tehran, Iran.

${ }^{2}$ Islamic Azad University, Department of Plant Protection, Khorramabad Branch, 68135 Khorramabad, Iran.

*Corresponding author (msco_1381@yahoo.com).

${ }^{3}$ Iranian Research Institute of Plant Protection, P.O. Box 145419395, Tehran, Iran.

${ }^{4}$ University of Tehran, University College of Agriculture and Natural Resources, Department of Plant Protection, P.O. Box 4111, Karaj, Iran. Received: 29 July 2011.

Accepted: 18 May 2012. et al., 2005; Kellouche and Soltani, 2006; Wang et al., 2009). They also affect reproductive parameters, such as net reproductive rate $\left(\mathrm{R}_{0}\right)$, intrinsic rate of increase $\left(\mathrm{r}_{\mathrm{m}}\right)$, finite rate of increase $(\lambda)$, generation time (T) (Hui-Dong et al., 2004; Zanuncio et al., 2005; Mahmoudvand et al., 2011b), pre-oviposition, oviposition and post-oviposition periods (Josan and Singh, 2000; Hamedi et al., 2010), hatchability (Sammour et al., 2008), adult longevity (Cutler et al., 2005; Suh et al., 2009), egg size (Fujiwara et al., 2002), and sex ratio (Delpuech and Meyet, 2003).

In contrast with neurotoxic pesticides, which account for most of the active ingredients registered in all countries, insect growth regulators (IGRs) are targeting molt and metamorphosis and are more selective (Dhadialla et al., 1998; Hoffmann and Lorenz, 1998). A group of IGRs are benzoylphenylurea (BPU) compounds that interfere with insect growth, disturb molting, and deform the cuticle (Mian and Mulla, 1982; Reynolds, 1987). Because of their selectivity properties and efficacy on immature stages, BPUs can be used in Integrated Pest Management (IPM) programs (Wright and Retnakaran, 1987; Moser et al., 1992). Hexaflumuron [1-[3,5-dichloro-4-(1,1,2,2tetrafluoroethoxy)phenyl]-3-(2,6-difluorobenzoyl) urea] is a BPU insecticide that inhibits chitin synthesis and interrupts the molting process in target insects. It has ingestion, contact, and ovicidal toxicity (Sbragia et al., 1983; El-Barkey et al., 2009; Mahmoudvand et al., 2011a). The impacts of hexaflumuron's sublethal effects on insects have been previously examined (Vasuki and Rajavel, 1992; Coppen and Jepson, 1996; Marco and Castañera, 1996; Abo-Elghar et al., 2003; Kellouche and Soltani, 2006; Bakr et al., 2009). 
Since the last decade, P. xylostella has become a serious pest for members of the Brassicaceae crop family in Tehran Province. Iran. Based on our knowledge, no insecticide has been registered yet in Iran to control it. The present study is focused on the effects of sublethal doses of the IGR hexaflumuron on some biological parameters of the diamondback moth. Some data from this project were previously reported (Mahmoudvand et al., 2011c; 2012). Total number of eggs laid by females, sex ratio, pupation, and adult emergence (in parents and the next generation), oviposition period, and four reproductive parameters, including generation time, finite rate of increase, birth rate, and death rate of $P$. xylostella were reported here.

\section{MATERIALS AND METHODS}

\section{Insect rearing}

The primary population of $P$. xylostella was collected from cauliflower (Brassica oleracea L. var. botrytis) (Brassicaceae) crops in Shahre-Rey in southern Tehran, Iran. Approximately 500 P. xylostella adults were released in a plastic cage $(50 \mathrm{~cm} \times 30 \mathrm{~cm} \times 30 \mathrm{~cm})$; the eggs were then transferred to cauliflower leaves to continue their development. Insect stock was maintained at $25 \pm 1{ }^{\circ} \mathrm{C}$ and $65 \pm 5 \% \mathrm{RH}$ under a 16:8 h photoperiod in a growth chamber. The colony was reared two generations before testing.

\section{Bioassay of third-instar larvae}

The bioassay used a leaf dip method (Tabashnik and Cushing, 1987). Cabbage leaf disks ( $3 \mathrm{~cm}$ diameter) were dipped in seven concentrations of hexaflumuron (Consult 10\% EC, Dow Agro Sciences, Indianapolis, Indiana, USA) solutions containing $0.02 \%$ Tween- 80 for $30 \mathrm{~s}$. In the control group, leaf disks were dipped in water with $0.02 \%$ Tween- 80 . The treated leaf disks were allowed to dry at room temperature and were then placed in a plastic cup (3 $\mathrm{cm}$ depth and $5.5 \mathrm{~cm}$ diameter). Ten third-instar larvae that had been starved for $2 \mathrm{~h}$ were placed on the leaf disks. These tests were replicated four times and at least 60 third-instar larvae made up each concentration. Mortality was recorded $96 \mathrm{~h}$ after treatment. Data were analyzed with SAS software for probit analysis (SAS Institute, 1997). Values of $\mathrm{LC}_{10}$ and $\mathrm{LC}_{25}$ for leaf dip tests on third-instar P. xylostella were 0.59 and $0.91\left(\mathrm{mg} \mathrm{L}^{-1}\right)$ after $96 \mathrm{~h}\left(\chi^{2}=2.57, P=0.76\right)$.

\section{Treatment with sublethal hexaflumuron concentrations} Cabbage leaf disks treated with $\mathrm{LC}_{10}$ and $\mathrm{LC}_{25}$ hexaflumuron concentrations and the control were prepared in $0.02 \%$ Tween-80. After drying, 25 thirdinstar larvae that had been starved for $2 \mathrm{~h}$ were placed on treated leaves in a plastic cup (as described above). Eight replicates were measured for each treatment. Live larvae were transferred to fresh cabbage leaves after $96 \mathrm{~h}$ and allowed to continue their development until the pupal stage. Pupae were placed individually in a Petri dish $(8$ $\mathrm{cm}$ diameter) until adults emerged. Afterwards, 20 pairs of adults of each of the sublethal concentrations or control were selected and each pair (male and female) was put in a plastic cage $(14 \mathrm{~cm} \times 11 \mathrm{~cm} \times 5 \mathrm{~cm})$. A sugar solution $(10 \%)$ was used to feed moth adults. Adults were allowed to lay eggs on cabbage leaves placed in each cage. Leaves were replaced with fresh ones and the number of eggs laid was recorded daily. This process continued until the adult's death. Furthermore, pre-oviposition, oviposition, and post-oviposition periods were evaluated.

\section{Data analysis}

Data obtained were subjected to one-way ANOVA $(P<$ $0.05)$ after checking for normality. Means were compared with Tukey's studentized range test with significant differences at $P<0.05$. Differences in biological parameters were tested by the Jackknife method (Maia et al., 2000). All analyses were with SAS software (SAS Institute, 1997).

\section{RESULTS}

\section{Pupation rate and adult emergence percentage}

Pupation rate of the treated diamondback moth generation was significantly affected by hexaflumuron (Figure 1); however, no significant differences were found between the exposed and control groups in the offspring generation in the pupation trend (Parent: $F=63.55, P<0.0001$, df $=2,21$; Offspring: $F=1.56, P=0.2625, \mathrm{df}=2,9$ ). The percentage of adult emergence in specimens exposed to hexaflumuron was obviously lower than the control in the treated generation $(F=48.69, P<0.0001, \mathrm{df}=2,21)$, but this parameter in the $\mathrm{LC}_{10}$ and $\mathrm{LC}_{25}$ concentrations and control were similar in offspring $(F=1, P=0.4053$, df $=$ 2) (Figure 2).

\section{Total number of eggs and sex ratio}

Total number of eggs and sex ratio of treated and control specimens are shown in Table 1. Both sublethal

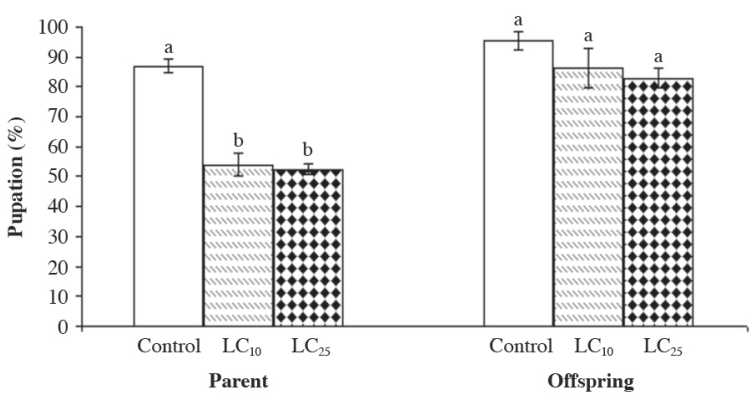

Figure 1. Effect of sublethal doses of hexaflumuron on pupation percentage of Plutella xylostella in parent and offspring generations (Parent: $\boldsymbol{F}=$ 63.55, $P>0.0001$, df $=2,21$; Offspring: $F=1.56, P=0.2625$, df $=2,9$ ) 


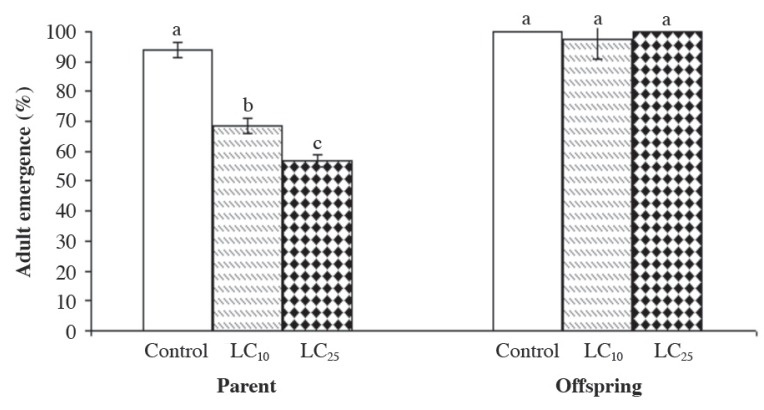

Figure 2. Effect of sublethal doses of hexaflumuron on adult emergence percentage of Plutella xylostella in parent and offspring generations (Parent: $F=48.69, P>0.0001$, df $=2,21$; Offspring: $F=1, P=0.4053$, df $=2,9$ ).

concentrations $\left(\mathrm{LC}_{10}\right.$ and $\left.\mathrm{LC}_{25}\right)$ caused a decrease in the total number of eggs laid by females as compared with the control. The total number of eggs differed significantly between $\mathrm{LC}_{10}$ and $\mathrm{LC}_{25}$ treatments $(F=814.43, P<$ $0.0001, \mathrm{df}=2,57)$. However, there was no significant difference in sex ratio between control and sublethal hexaflumuron concentrations $(F=0.5346, P=0.70$, df $=2,6)$.

\section{Oviposition period}

Table 2 shows the sublethal effects of hexaflumuron on pre-oviposition (time between adult emergence and first oviposition), oviposition, and post-oviposition periods of $P$. xylostella. Hexaflumuron at $\mathrm{LC}_{25}$ increased the preoviposition period $(F=6.95, P=0.0020, \mathrm{df}=2,57)$. The oviposition duration of the diamondback moth was lower than the control in the $\mathrm{LC}_{25}$ group $(F=4.12, P=0.0020$, $\mathrm{df}=2,57)$. In addition, hexaflumuron in both sublethal concentrations significantly declined the post-oviposition period of P. xylostella $(F=35.82, P<0.0001, \mathrm{df}=2,57)$.

Table 1. Comparison of number of eggs laid by all females and sex ratio of Plutella xylostella treated with sublethal doses of hexaflumuron and control.

\begin{tabular}{lcc}
\hline & $\begin{array}{c}\text { Total number of } \\
\text { eggs of females }\end{array}$ & Sex ratio $( \pm \mathrm{SE})$ \\
\hline Control & $3741.35 \pm 32.71 \mathrm{a}$ & $0.50 \pm 0.03 \mathrm{a}$ \\
$\mathrm{LC}_{10}$ & $3489.25 \pm 17.46 \mathrm{~b}$ & $0.46 \pm 0.03 \mathrm{a}$ \\
$\mathrm{LC}_{25}$ & $2491.65 \pm 15.28 \mathrm{c}$ & $0.43 \pm 0.05 \mathrm{a}$ \\
$P$ & $<0.0001$ & 0.5346 \\
$F$ & 814.43 & 0.70 \\
Df & 2,57 & 2,6 \\
\hline
\end{tabular}

Means with different letters in the same column are significantly different according to Tukey's test $(P<0.05)$

$\mathrm{LC}_{10}$ : concentration that killed $10 \%$ of population; $\mathrm{LC}_{25}$ : concentration that killed $25 \%$ of population; P: probability; Df: degree of freedom; SE: standard error.

\section{Reproduction parameters}

Effects of sublethal hexaflumuron concentrations on finite rate of increase $(\lambda)$, generation time $(T)$, birth rate $(b)$, and death rate $(d)$ of $P$. xylostella are reported in Table 3. Hexaflumuron at $\mathrm{LC}_{10}$ and $\mathrm{LC}_{25}$ concentrations significantly diminished $\lambda(F=29433.23, P<0.0001, \mathrm{df}$ $=2,57)$ and also decreased $b$ of the diamondback moth $(F$ $=9462.75, P<0.0001, \mathrm{df}=2,57)$. Generation time $(T)$ was delayed in the parent groups as compared with the control $(F=19970.60, P<0.0001$, df $=2,57)$, and $d$ at these two sublethal concentrations significantly increased $(F=99999.99, P<0.0001$, df $=2,57)$.

Table 3. Comparison of finite rate of increase $(\lambda)$, generation time $(T)$ birth rate $(b)$, and death rate $(d)$ of Plutella xylostella treated with sublethal doses of hexaflumuron and control.

\begin{tabular}{lcccc}
\hline & $\lambda\left(\mathrm{d}^{-1}\right)$ & $T(\mathrm{~d})$ & Birth rate $(b)$ & Death rate $(d)$ \\
\hline Control & $1.19 \pm 0.00 \mathrm{a}$ & $24.80 \pm 0.01 \mathrm{c}$ & $0.21 \pm 0.00 \mathrm{a}$ & $0.036 \pm 0.00 \mathrm{c}$ \\
$\mathrm{LC}_{10}$ & $1.15 \pm 0.00 \mathrm{~b}$ & $26.15 \pm 0.02 \mathrm{~b}$ & $0.19 \pm 0.00 \mathrm{~b}$ & $0.051 \pm 0.00 \mathrm{~b}$ \\
$\mathrm{LC}_{25}$ & $1.10 \pm 0.00 \mathrm{c}$ & $30.58 \pm 0.02 \mathrm{a}$ & $0.16 \pm 0.00 \mathrm{c}$ & $0.063 \pm 0.00 \mathrm{a}$ \\
$P$ & $<0.0001$ & $<0.0001$ & $<0.0001$ & $<0.0001$ \\
$F$ & 29433.23 & 19970.60 & 9462.75 & 99999.99 \\
Df & 2,57 & 2,57 & 2,57 & 2,57 \\
\hline
\end{tabular}

Means with different letters in the same column are significantly different according to Tukey's test $(P<0.05)$

$\mathrm{LC}_{10}$ : concentration that killed $10 \%$ of population; $\mathrm{LC}_{25}$ : concentration that killed $25 \%$ of population; P: probability; Df: degree of freedom.

\section{DISCUSSION}

Results of the leaf dip bioassay indicated that hexaflumuron has a good toxicity on the third-instar larvae of $P$. xylostella. Furthermore, hexaflumuron had acceptable effects on pupation, adult emergence, oviposition, and reproductive factors of $P$. xylostella at sublethal concentrations.

In this study, the number of eggs laid by females decreased with hexaflumuron at sublethal concentrations. This suggests that hexaflumuron has a good effect on the physiology of P. xylostella and causes reduced egglaying. Similarly, Abo-Elghar et al. (2003) and Kellouche and Soltani (2006) used different insects and reported a decline fecundity of Callosobruchus maculatus Fabricius after exposure to hexaflumuron. Sial and Brunner (2010) reported a decrease in fecundity of Choristoneura rosaceana (Harris) (Lepidoptera: Totricidae) treated with the IGR pyriproxyfen. Sex ratio of the offspring generation changed in some cases when adults were exposed to pesticides. This can occur due to the effect on the fertilization of the females' ova. This phenomenon

Table 2. Comparison of oviposition period $(\mathrm{d} \pm \mathrm{SE})$ of Plutella xylostella treated with sublethal doses of hexaflumuron.

\begin{tabular}{|c|c|c|c|c|c|c|}
\hline & \multirow[b]{2}{*}{ Control } & \multicolumn{2}{|c|}{ Hexaflumuron } & \multirow[b]{2}{*}{$P$} & \multirow[b]{2}{*}{$F$} & \multirow[b]{2}{*}{$\mathrm{df}$} \\
\hline & & $\mathrm{LC}_{10}$ & $\mathrm{LC}_{25}$ & & & \\
\hline Pre-oviposition period & $0.65 \pm 0.10 b$ & $1.35 \pm 0.23 \mathrm{ab}$ & $1.75 \pm 0.26 \mathrm{a}$ & 0.0020 & 6.95 & 2,57 \\
\hline Oviposition period & $15.7 \pm 0.73 a$ & $15.55 \pm 1.00 \mathrm{a}$ & $12.65 \pm 0.14 b$ & 0.0213 & 4.12 & 2,57 \\
\hline Post-oviposition period & $4.30 \pm 0.27 a$ & $2.00 \pm 0.24 b$ & $1.70 \pm 0.19 b$ & $<0.0001$ & 35.82 & 2,57 \\
\hline
\end{tabular}

Means with different letters in the same row are significantly different according to Tukey's test $(P<0.05)$.

$\mathrm{LC}_{10}$ : concentration that killed $10 \%$ of population; $\mathrm{LC}_{25}$ : concentration that killed $25 \%$ of population; P: probability; Df: degree of freedom; SE: standard error. 
has occurred particularly in haplodiploid insects. Another reason could be the differential survival of treated males and females before the adult stage (Idris and Grafius, 1993). According to these results, hexaflumuron was unable to change the sex ratio of the diamondback moth. Similarly, indoxacarb had no effect on the sex ratio of P.xylostella (Mahmoudvand et al., 2011b). A major effect of IGRs is in the molting process that disrupts cuticle synthesis. In this study, sublethal hexaflumuron concentrations in the treated generation decreased the pupation rate and adult emergence of $P$. xylostella. This effect was not repeated in the next generation. It is indicated that hexaflumuron had a direct impact on pupation rate and adult emergence, but the next generation exhibited no effects in these parameters. In accordance with the present study, Marco and Viñuela (1999) observed that sublethal hexaflumuron concentrations had a significant decrease on the percentage of pupation and adult emergence rate of Ephestia kuehniella Zeller (Lepidoptera: Pyralidae). Vasuki and Rajavel (1992) also stated that hexaflumuron significantly decreased the adult emergence rate of Anopheles stephensi (Diptera: Culicidae). Analogous to this study's results, Mahmoudvand et al.(2011b) reported that sublethal concentrations of indoxacarb decreased the pupation rate and adult emergence of P. xylostella in the parent generation, but that these parameters were unchanged in the next generation. The oviposition and post-oviposition period of $P$. xylostella was shorter in the treatment groups than in the control in our study. On the other hand, sublethal concentrations postponed inception of female oviposition. Hexaflumuron delayed the start of oviposition by more than $1 \mathrm{~d}$, whereas this period was $0.65 \mathrm{~d}$ for the control. In accordance with the present results, Josan and Singh (2000) showed that the oviposition period of $P$. xylostella significantly decreased when treated with lufenuron which is a CSI insecticide. In addition, Yin et al. (2008) reported that the pre-oviposition period of the diamondback moth was increased with spinosad. In this study, ova were affected by hexaflumuron and this caused the oviposition period to decrease. On the other hand, death of parent group females was low after oviposition as compared with the control.

Hexaflumuron sublethal concentrations reduced finite rate of increase $(\lambda)$ and birth rate $(b)$ of $P$. xylostella, but increased death rate $(d)$ and generation time $(T)$. In addition, Mahmoudvand et al. (2011b) recently reported decreases in the intrinsic rate of increase $\left(r_{m}\right)$, net reproductive rate $\left(R_{0}\right)$, and gross reproduction rate (GRR) along with an increase in the doubling time $\left(D_{t}\right)$ of P. xylostella after exposure to hexaflumuron. Similarly, Sáenz-de-Cabezón et al. (2006) stated that $r_{m}$ and $\lambda$ of Tetranychus urticae (Koch) (Acari: Tetranychidae) decreased after being treated with the IGR triflumuron. Wang et al. (2008) remarked that biological parameters of Myzus persicae (Sulzer) (Hom.: Aphididae) were influenced by imidacloprid. In the study by Yin et al . (2008), $\mathrm{LC}_{25}$ and $\mathrm{LC}_{50}$ spinosad concentrations decreased $\lambda$ and increased $T$ in P. xylostella. We showed that the effect of hexaflumuron decreases the number of eggs and $\lambda$ in P. xylostella, and Hui-Donget et al. (2004) found that emamectin also decreases these parameters in $P$. xylostella.

\section{CONCLUSION}

In conclusion, results suggest that hexaflumuron has a good ingestion effect against the Plutella xylostella larval stage. Hexaflumuron also reduced pupation rate, adult emergence, number of total eggs, and biological parameters of P.xylostella. Furthermore, hexaflumuron reduced the oviposition and post-oviposition period and increased the pre-oviposition period, whereas it had no impact on the sex ratio of the diamondback moth.

\section{ACKNOWLEDGEMENTS}

We thank the Agricultural Entomology section of the Iranian Research Institute of Plant Protection, Tehran, Iran and the Entomology section of the Department of Plant Protection of Shahed University, Tehran, Iran.

Disminución en pupación y emergencia de adultos de Plutella xylostella (L.) tratados por hexaflumuron. Plutella xylostella (L.), una plaga oligofaga, es una importante plaga de crucíferas en la provincia de Teherán, Irán. Hexaflumuron, un insecticida regulador de crecimiento de insectos, tiene buenos efectos sobre estados inmaduros de insectos. El objetivo de este estudio es investigar los efectos de dos concentraciones subletales $\left(\mathrm{LC}_{10}\right.$ y $\mathrm{LC}_{25}$ ) de hexaflumuron sobre algunos parámetros de larvas de P. xylostella tales como tasa de nacimiento (b) y tasa de mortalidad $(d)$, tasa finita de aumento $(\lambda)$, tiempo de generación $(T)$, proporción de sexos, tasa de pupación, emergencia de adultos, y algunos otros parámetros. Los resultados mostraron que hexaflumuron redujo el número total de huevos y ovipostura y períodos de post-ovipostura, pupación, y emergencia de adultos en la generación tratada, $b$ y $\lambda$. Hexaflumuron además aumentó $T, d$ y el período pre-ovipostura. Sin embargo, la proporción de sexos, porcentaje de pupación, y emergencia de adultos en la generación producto no fueron afectados por hexaflumuron. En conclusión, estos resultados indicaron que las concentraciones subletales de hexaflumuron pueden afectar los parámetros biológicos de P. xylostella.

Palabras clave: Plutella xylostella, hexaflumuron, subletal, tasa de nacimiento, tasa de mortalidad, período de ovipostura. 


\section{LITERATURE CITED}

Abo-Elghar, G.E., A.E. El-Sheikh, F.M. El-Sayed, H.M. ElMaghraby, and H.M. El-Zun. 2003. Persistence and residual activity of an organophosphate, pirimiphos-methyl, and three IGRs, hexaflumuron, teflubenzuron and pyriproxyfen, against the cowpea weevil, Callosobruchus maculatus (Coleoptera: Bruchidae). Pest Management Science 60:95-102.

Bakr, R.F.A., M.I.A. Mohamme, E.M. El-Gammal, and N.M. Mahdy. 2009. Biological effects of chitin-synthesis inhibitor, hexaflumuron compound on the desert locust, Schistocerca gregaria (Forskal). Egyptian Academic Journal of Biological Science 1:49-57.

Coppen, G.D.A., and P.C. Jepson. 1996. The effects of the duration of exposure on the toxicity of diflubenzuron, hexaflumuron and teflubenzuron to various stages of II instar Schistocerca gregaria. Pesticide Science 46:191-197.

Curkovic, T., and J.F. Brunner. 2005. Residual and sublethal effects of an attracticide formulation on Choristoneura rosaceana (Harris), Pandemis pyrusana Kearfott, and Cydia pomonella (L.) (Lepidoptera: Tortricidae). Crop Protection 24:637-641.

Curkovic, T., J.F. Brunner, and J.J. Brown. 2009. Toxicity of fieldaged permethrin-loaded attracticides on Choristoneura rosaceana (Harris) and Pandemis pyrusana Kearfott (Lepidoptera: Tortricidae) adult males and females. Chilean Journal of Agricultural Research 69:21-29.

Cutler, G.C., C.D. Scott-Dupree, J.H. Tolman, and C.R. Harris. 2005. Acute and sublethal toxicity of novaluron, a novel chitin synthesis inhibitor, to Leptinotarsa decemlineata (Coleoptera: Chrysomelidae). Pest Management Science 61:1060-1068.

Delpuech, J.M., and J. Meyet. 2003. Reduction in the sex ratio of the progeny of a parasitoid wasp (Trichogramma brassicae) surviving the insecticide chlorpyrifos. Archives of Environmental Contamination and Toxicology 45:203-208.

Dhadialla, T.S., G.R. Carlson, and D.P. Le. 1998. New insecticides with ecdysteroidal and juvenile hormone activity. Annual Review of Entomology 43:545-569.

El-Barkey, N.M., A.E. Amer, and M.A. Kandeel. 2009. Ovicidal activity and biological effects of radiant and hexaflumuron against eggs of pink bollworm, Pectinophora gossypiella (Saunders) (Lepidoptera: Gelechiidae). Egyptian Academy Journal of Biology Science 2:23-36.

Fujiwara, Y.T., T. Takahashi, T. Yoshioka, and F. Nakasuji. 2002. Changes in egg size of the diamondback moth, Plutella xylostella (Lepidoptera: Yponomeutidae) treated with fenvalerate at sublethal doses and viability of the eggs. Applied Entomology and Zoology 37:103-109.

Galvan, T.L., R.L. Koch, and W.D. Hutchison. 2005. Effects of spinosad and indoxacarb on survival, development and reproduction of the multicolored Asian lady beetle (Coleoptera: Coccinellidae). Biological Control 34:108-114.

Golmohammadi, G., M. Hejazi, S. Iranipour, and S.A. Mohammadi. 2009. Lethal and sublethal effects of endosulfan, imidacloprid and indoxacarb on first instar larvae of Chrysoperla carnea (Neu.: Chrysopidae) under laboratory conditions. Journal of Entomology Society of Iran 28:37-47.

Hamedi, N., Y. Fathipour, and M. Saber. 2010. Sublethal effects of fenpyroximate on life table parameters of the predatory mite Phytoseius plumifer. BioControl 55:271-278.

Haynes, K.F. 1988. Sublethal effects of neurotoxic insecticides on insect behavior. Annual Review of Entomology 33:149-168.

Hoffmann, K.H., and M.W. Lorenz. 1998. Recent advances in hormones in insect pest control. Phytoparasitica 26:1-8.

Hui-Dong, L., Z. Fang-Qiang, and L. Wan-Chun. 2004. Toxicity of emamectin to the diamondback moth; Plutella xylostella and the effects on survivors of parent generation treated with sub-lethal dosage. Acta Entomologica Sinica 47:193-197.

Idris, A.B., and E. Grafius. 1993. Differential toxicity of pesticides to Diadegma insulare (Hymenoptera: Ichneumonidae) and its host, the diamondback moth (Lepidoptera: Plutellidae). Journal of
Economic Entomology 86:529-536.

Josan, A., and G. Singh. 2000. Sublethal effects of lufenuron on the diamondback moth, Plutella xylostella (Linnaeus). International Journal of Tropical Insect Science 20:303-308.

Jun, W., Y. Daqiang, L. Genfa, and Z. Fengfan. 1999. Effects of dimehypo (disodium 2-methylaminotrimethylene dithiosulfonate) on growth and cocooning of the silkworm, Bombyx mori (Lepidoptera: Saturnidae). Pesticide Science 55:1070-1076.

Kellouche, A., and N. Soltani. 2006. Impact of hexaflumuron, a chitin synthesis inhibitor, on growth, development and reproductive performance of the progeny in Callosobruchus maculatus after adult treatments. African Journal of Agricultural Research 1:5764.

Mahmoudvand, M., H. Abbasipour, A. Garjan, and A. Bandani 2011b. Sublethal effects of indoxacarb on the diamondback moth, Plutella xylostella (L.) (Lepidoptera: Yponomeutidae). Applied Entomology and Zoology 46:75-80.

Mahmoudvand, M., H. Abbasipour, A.S. Garjan, and A.R. Bandani. 2011c. Sublethal effects of hexaflumuron on development and reproduction of the diamondback moth, Plutella xylostella (Lepidoptera: Yponomeutidae). Insect Science18:689-696.

Mahmoudvand, M., H. Abbasipour, A. Sheikhi-Garjan, and A.R. Bandani. 2012. Life expectancy (ex) and stable age distribution (Cx) of Plutella xylostella (L.) (Lep.: Yponomeutidae), exposed to sublethal doses of hexaflumuron. Archives of Phytopathology and Plant Protection 45:318-324.

Mahmoudvand, M., A. Sheikhi Garjan, and H. Abbasipour. 2009. Toxicity of neurotoxin insecticides on Diamondback moth, Plutella xylostella (Lep.: Plutellidae). p. 68-69. Proceeding of the $6^{\text {th }}$ Asia-Pacific Congress of Entomology, Beijing, China.

Mahmoudvand, M., A. Sheikhi-Garjan, and H. Abbasipour. 2011a. Ovicidal effectof some insecticides on the diamondback moth, Plutella xylostella (L.) (Lepidoptera: Yponomeutidae). Chilean Journal of Agricultural Research 71:226-230.

Maia, A.D.H., J.B. Alfredo, and C. Campanhola. 2000. Statistical inference on associated fertility life table parameters using Jackknife technique: Computational Aspects. Journal of Economic Entomology 93:511-518.

Marco, V., and P. Castañera. 1996. Eficacia de aplicaciones foliares de insecticidas, con Torre de Potter, sobre adultos de Aubeonymus mariaefranciscae Roudier (Coleóptera: Curculionidae). Boletín de Sanidad Vegetal, Plagas 22:659-666.

Marco, V., and E. Viñuela. 1999. Efectos del RCI hexaflumuron sobre larvas de la polilla mediterránea de la harina Ephestia kuehniella Zeller (Lepidoptera: Pyralidae) en aplicación tópica y por ingestión. Influencia de la edad de las larvas tratadas. Boletin de Sanidad Vegetal, Plagas 25:59-68.

Mian, L.S., and M.S. Mulla. 1982. Biological and environmental dynamics of insect growth regulators (IGRs) as used against Diptera of public health importance. Residue Review 84:27-112.

Michaud, J.P., and A.K. Grant. 2003. IPM-compatibility of foliar insecticides for citrus: indices derived from toxicity to beneficial insects from four orders. Journal of Insect Science 3:18.

Moser, B.A., P.G. Koehler, and R.S. Patterson. 1992. Effect of methoprene and diflubenzuron on larval development of the cat flea (Siphonaptera: Pulicidae). Journal of Economic Entomology 85:112-116

Mota-Sanchez, D., P.S. Bills, and M.E. Whalon. 2002. Arthropod resistance to pesticides: status and overview. p. 241-272. In W.E. Wheeler (ed.) Pesticides in agriculture and the environment Marcel Dekker, New York, USA.

Perez, C.J., A.M. Shelton, and R.C. Derksen. 1995. Effects of field application technology and Bacillus thuringiensis subspecies on management of $B$. thuringiensis subsp. kurstarki-resistant Diamond Back (Lepidoptera: Plutellidae). Journal of Economic Entomology 88:1113-1119.

Reynolds, S.E. 1987. The cuticle, growth and moulting in insects: the essential background to the action of acylurea insecticides. Pest Science 20:131-146.

Sáenz-de-Cabezón, F.J., E. Martínez-Villar, F. Moreno, V. Marco, 
and I. Pérez-Moreno. 2006. Influence of sublethal exposure to triflumuron on the biological performance of Tetranychus urticae Koch (Acari: Tetranychidae). Spanish Journal of Agricultural Research 4:167-172.

Sammour, E.A., M.A. Kandil, and W.F. Abdel-Aziz. 2008. The reproductive potential and fate of chlorfluazuron and leufenuron against cotton Leafworm Spodoptera littoralis (Boisd.) AmericanEurasian Journal of Agricultural \& Environmental Science 4:6267.

Sarfraz, M., L.M. Dosdall, and B.A. Keddie. 2006. Diamondback moth host plant interaction: Implication for pest management. Crop Protection 625-639.

SAS Institute. 1997. SAS/STAT guide for personal computers. Version 6.12. SAS Institute, Cary, North Carolina, USA.

Sbragia, R.J., B. Bisabri-Ershadi, R.H. Rigterink, D.P. Clifford, and R. Dutton. 1983. XRD-473, a new acylurea insecticide effective against Heliothis. p. 417-424. Proceedings $10^{\text {th }}$ International Congress of Plant Protection: Plant Protection for Human Welfare, Brighton. 20-25 November. British Crop Protection Council, Hampshire, UK.

Sial, A.A., and J.F. Brunner. 2010. Lethal and sublethal effects of an insect growth regulator, pyriproxyfen, on obliquebanded leafroller (Lepidoptera: Tortricidae). Journal of Economic Entomology 103:340-347.

Suh, C.P.C., D.B. Orr, and J.W. Van Duyn. 2009. Effect of Insecticides on Trichogramma exiguum (Trichogrammatidae: Hymenoptera) preimaginal development and adult survival. Journal of Economic Entomology 93:577-583.
Tabashnik, B.E., and N.L. Cushing. 1987. Leaf residue vs. topical bioassays for assessing insecticide resistance in the diamondback moth, Plutella xylostella L. FAO Plant Protection Bulletin 35:1114.

Vasuki, V., and A.R. Rajavel. 1992. Influence of short time exposure to an insect growth regulator, hexaflumuron, on mortality and adult emergence of vector mosquitoes. Memoirs of Institute Oswaldo Cruz 87:275-283.

Wang, D.X., H. Qiu, X.X. Ren, W.Z. Zhang, and K.Y. Wang. 2009. Sublethal effects of spinosad on survival, growth and reproduction of Helicoverpa armigera (Lepidoptera: Noctuidae). Pest Management Science 65:223-227.

Wang, X.Y., Z.Q. Yang, Z.R. Shen, J. Lu, and W.B. Xu. 2008. Sublethal effects of selected insecticides on fecundity and wing dimorphism of green peach aphid (Hom., Aphididae). Journal of Applied Entomology 132:135-142.

Wright, J.E., and A. Retnakaran (eds.) 1987. Chitin and benzoylphenyl ureas. W. Junk Publishers, Dordrecht, The Netherlands.

Yin, X.H., Q.J. Wu, X.F. Li, Y.J. Zhang, and B.Y. Xu. 2008. Sublethal effects of spinosad on Plutella xylostella (Lepidoptera: Yponomeutidae). Crop Protection 27:1385-1391.

Zanuncio, T.V., J.C. Zanuncio, J.E. Serrao, R.S. Medeiros, T.B. Pinon, and C.A. Sediyama. 2005. Fertility and life expectancy of the predator Supputius cincticeps (Heteroptera: Pentatomidae) exposed to sublethal doses of permethrin. Biological Research 38:31-39. 